\title{
COVID-19 and medical education in Africa: a cross sectional analysis of the impact on medical students
}

\author{
Alec Bernard ${ }^{1}$, Gnendy Indig ${ }^{1}$, Nicole Byl ${ }^{1}$, Amani Nureddin Abdu², Dawit Tesfagiorgis Mengesha ${ }^{2 *}$ (D), \\ Bereket Alemayehu Admasu² and Elizabeth Holman
}

\begin{abstract}
Background: The African continent currently experiences $25 \%$ of the global burden of disease with only $1.3 \%$ of the world's healthcare workers. The COVID-19 pandemic has caused unprecedented disruption to medical education systems, increasing the strain on already-vulnerable regions. Our study examines the impact of COVID-19 on medical students across 33 countries in the African continent.
\end{abstract}

Methods: A 39-item anonymous electronic survey was developed and distributed to medical students across Africa through social networks to assess the impact of the COVID-19 pandemic on medical education. The survey assessed the domains of: class structure changes and timing, patient interactions, exam administration, learning environment satisfaction, mental health impacts, and volunteer opportunities/engagement.

Results: 694 students across 33 countries participated. $80 \%$ of respondents had their classes suspended for varied lengths of time during the pandemic, and from these students 59\% of them resumed their classes. $83 \%$ of students felt they were in a supportive learning environment before the pandemic, which dropped to $32 \%$ since the start. The proportion of students taking exams online increased $(6-26 \%, p<0.001)$ and there was a decrease in the proportion of students seeing patients as a part of their education $(72-19 \%, \mathrm{p}<0.001)$.

Conclusions: COVID-19 is harming medical students in Africa and is likely to worsen the shortage of the future's healthcare workforce in the region. Pandemic-related impacts have led to a degradation of the learning environment of medical students. Medical schools have shifted online to differing degrees and direct patient-care in training of students has decreased. This study highlights the urgent need for flexible and innovative approaches to medical education in Africa.

Keywords: COVID-19, Pandemic, Africa, Health disparities, Medical education, Medical students

\section{Background}

The pandemic-related disruption to medical education has worrisome implications for global public health. In Africa, $1.3 \%$ of the world's health care workers (HCW)

*Correspondence: d.tesfa39@gmail.com

${ }^{2}$ St.Paul's Hospital Millennium Medical College, 1271 Swaziland Street,

Addis Ababa, Ethiopia

Full list of author information is available at the end of the article care for people who experience $25 \%$ of the global burden of disease [1]. Africa has $2.3 \mathrm{HCW}$ per 1000 population, compared with 25 per 1000 in the Americas. Estimates suggest that the current training is insufficient to even maintain the current density of HCW [2]. This shortage is likely to be exacerbated in parts of the world less able to adapt their medical education systems to the demands of the COVID-19 pandemic. At the time of writing, COVID-19 has infected over 203 million people with

(c) The Author(s) 2021. Open Access This article is licensed under a Creative Commons Attribution 4.0 International License, which permits use, sharing, adaptation, distribution and reproduction in any medium or format, as long as you give appropriate credit to the original author(s) and the source, provide a link to the Creative Commons licence, and indicate if changes were made. The images or other third party material in this article are included in the article's Creative Commons licence, unless indicated otherwise in a credit line to the material. If material is not included in the article's Creative Commons licence and your intended use is not permitted by statutory regulation or exceeds the permitted use, you will need to obtain permission directly from the copyright holder. To view a copy of this licence, visit http://creativecommons.org/licenses/by/4.0/. The Creative Commons Public Domain Dedication waiver (http://creativeco mmons.org/publicdomain/zero/1.0/) applies to the data made available in this article, unless otherwise stated in a credit line to the data. 
over 4.3 million deaths, causing unprecedented disruption to health and education systems [3]. Eleven countries in Africa lack even a single medical school, and 24 countries have only one medical school [4]. There are estimated to be a total of 143 medical schools in all of Sub-Saharan Africa graduating around 10,000 physicians annually [5]. To date, there is no comprehensive information about the impact of COVID-19 and related mitigation measures on medical education in Africa. Our study serves to fill this gap by examining the impact of the pandemic on medical students across the African continent.

According to the United Nations Educational, Scientific and Cultural Organization (UNESCO), at its peak, the pandemic affected over $75 \%$ of students across the world, with a higher percentage impacted in Africa [6]. The reactions of medical school administrators to this unprecedented stressor have varied, ranging from pausing all educational activities, to graduating students early to assist in fighting the pandemic [7, 8]. Additionally, E-learning has emerged as a central strategy in continuing education in the era of COVID-19 [9]. However, many low- and lower-middle income countries (LMIC) struggle with e-learning due to challenges with infrastructure, resource availability, communication, and social barriers [10]. A recent review of the transition to e-learning in pharmacy schools in Africa found numerous barriers related to poor accessibility in rural areas, high cost of internet data, and poor infrastructure in many areas $[11,12]$.

Furthermore, students are likely to face new challenges in the learning environment. Even before the pandemic, medical students were already at a greater risk for mental health problems than their matched peers [13]. The shift away from in-person education deprives students of social and professional interactions to the possible detriment of their education and mental well-being and we must understand the ways the pandemic has impacted students' learning environment.

Disruptions in medical training have the potential for largely detrimental impacts on the public health of a region already facing a disproportionate burden of disease. A thorough understanding of the disruption caused by the COVID-19 pandemic is necessary for the development of policies to limit the harm of this and future stressors to ensure the continued health of a region already facing a devastating shortage of trained providers. We examined medical students' perspectives of the impact of the pandemic on their medical education across various domains in order to inform the development of future policy. Specifically, we strove to answer the following questions: Was medical education suspended during the COVID-19 pandemic in Africa? How were the learning environment, student mental health, and perceptions of safety impacted? And was there a shift in the format of classes?

\section{Methods}

Study Design: While there are long-standing rigorously validated survey instruments like the Dundee Ready Educational Environment Measure (DREEM) for use in health professions education, existing instruments may lack content validity since they were not developed with this unprecedented global stressor in mind [14]. A review of existing medical education survey instruments and COVID-19 surveys cataloged on the PhenX Toolkit website [15] determined that there was no single instrument that appeared well targeted to assessment of medical education during the COVID-19 pandemic in Africa. Accordingly, the decision was made to develop a novel survey instrument to conduct research specific to the impact of COVID-19 on medical education in Africa. Given the highly situational nature of this aim, we believe that a new instrument was needed in order to enhance key measurement properties like content and construct validity.

Experts in survey methodology and medical education at the University of Michigan Medical School (UMMS) developed a 39-item survey assessing the following domains: class structure changes and timing, patient interactions, exam administration, learning environment satisfaction, mental health impacts, and volunteer opportunities/engagement. The survey development team consisted of all authors, two professors of medical education, and faculty members of the UMMS office of evaluation and assessment. The survey was composed of Likert scale, dichotomous, and free-response items. It was modified with the assistance of students in St. Paul's Millennium Medical College (SPHMMC) through pilot administration and cognitive interviewing to ensure readability and ease of understanding in multiple countries. The survey underwent three rounds of pilot administration and interviewing with four students at SPHMMC per round. The survey was edited for readability and ease of understanding between each round. Full survey available in Additional file 1.

IRB approval was granted via St. Paul's Millennium Medical College Institutional Review Board. All research was performed in accordance with the Declaration of Helsinki and approved by an appropriate ethics committee. Informed consent to participate was elicited prior to survey administration with an option to opt-out prior to survey administration.

Survey Distribution: This anonymous electronic survey was sent to medical students across African countries to assess the impact of the COVID-19 pandemic on medical students (Google Forms, CA). Survey administration 
took place from September 15th to October 5th, 2020. The survey was widely distributed throughout Africa via the International Federation of Medical Students Association (IFMSA) social network groups, including Facebook, WhatsApp, and Telegram. Participants were medical students, ranging from pre-clinical to final year medical students. The IFMSA is one of the largest medical student organizations with 1.3 million students across 123 countries worldwide, including all but 14 countries in Africa. Student representatives from each country apply for membership in IFMSA and after a 1-year probationary period, become full members. Representatives of IFMSA were asked to distribute the survey further within their medical schools to reach respondents who were not directly members of IFMSA.

\section{Data analysis}

Quantitative analysis was completed using IBM SPSS version 27. Descriptive statistics were calculated for sociodemographic variables, as well as responses to each survey question. A Wilcoxon Signed Rank test was used to assess the differences between pretest and posttest responses. A Mann-Whitney U test was used to determine the pandemics impact on students' mental health. Responses were analysed in aggregate.

\section{Results}

Sociodemographic information of survey respondents is shown in Table 1. The locations of medical students represented in our sample are shown in Fig. 1.

Respondents represent 107 medical schools across 33 countries. The median medical schools per country is 3 with interquartile range of 2 . The median respondents per medical school is 5 with interquartile range of 6.5 . There are a total of 143 medical schools in Africa, with around 10,000 graduating physicians annually [5]. The nature of our social media recruitment does not allow estimates of the total number of students contacted by our study.

\section{Educational disruption due to COVID-19}

When asked about disruptions to their education, the majority of students, $80 \%$, had their classes suspended during the pandemic, and from these students $59 \%$ of them resumed their class by the time of the study. Of the students whose classes were suspended and resumed, $70 \%$ of students reported online classes, with $19 \%$ reporting hybrid classes. $17 \%$ of students resumed their education in person. Among students without suspended classes, $50 \%$ reported a change to online coursework and $26 \%$ continued in person. There were no significant differences in the proportion of pre-clinical and clinical students who had their classes suspended $(\mathrm{p}=0.067)$, who
Table 1 Sociodemographic information for the study sample

\begin{tabular}{ll}
\hline Variable & $\begin{array}{l}\text { Frequency } \\
(\mathbf{n}=694)\end{array}$ \\
\hline Sex & \\
Male & $335(48 \%)$ \\
Female & $347(49 \%)$ \\
Prefer not to say & $11(2 \%)$ \\
No Response & $1(0 \%)$ \\
Current Enrolment Phase* & \\
Preclinical Education & $194(28 \%)$ \\
Clinical Education & $490(71 \%)$ \\
No Response & $10(1 \%)$ \\
Age in Years & \\
Median & 23 \\
Interquartile Range & 3
\end{tabular}

*Generally, the first two years are preclinical education, followed by at least partial clinical education in years three and beyond

resumed classes $(\mathrm{p}=0.061)$, or who endorsed a change in format after resumption $(\mathrm{p}=0.870)$. Medical school closures also varied significantly in length and the average length of closure by country is presented in Fig. 2 .

\section{Perspective of learning environment before and after COVID-19 related disruptions}

Students were asked about the learning environment. Overall, before the pandemic $83 \%$ of students felt they were in a supportive learning environment and since the pandemic, only $32 \%$ felt they were in a supportive learning environment. Even of the students who felt they were in a supportive learning enviroment before the pandemic, $67 \%$ felt that they were not in a supportive environment since the pandemic began.

Specifically, students were asked about their satisfaction levels with varying aspects of the teaching environement before and during the COVID-19 pandemic. After the start of the pandemic, 33\% of students reported being "very dissatisfied" or "dissatisfied with the ease of reaching faculty for questions compared with $8 \%$ of students reporting dissatisfaction before the pandemic $(\mathrm{p}<0.001)$. Before COVID-19, 6\% of students reported dissatisfaction with faculty engagement. In contrast, since the start of the pandemic $37 \%$ of students were dissatisfied with faculty preparedness for classes. The change in satisfaction levels with aspects of the learning environment and the changes in online exams are shown in Fig. 3. When asked about positive impacts of the changes in the learning environment, 57\% of students selected increased flexibility of time and $38 \%$ selected decreased time spent community. Conversely, when discussing the negatives of the pandemic related changes, students cited 


\section{Survey Distribution Across Africa}

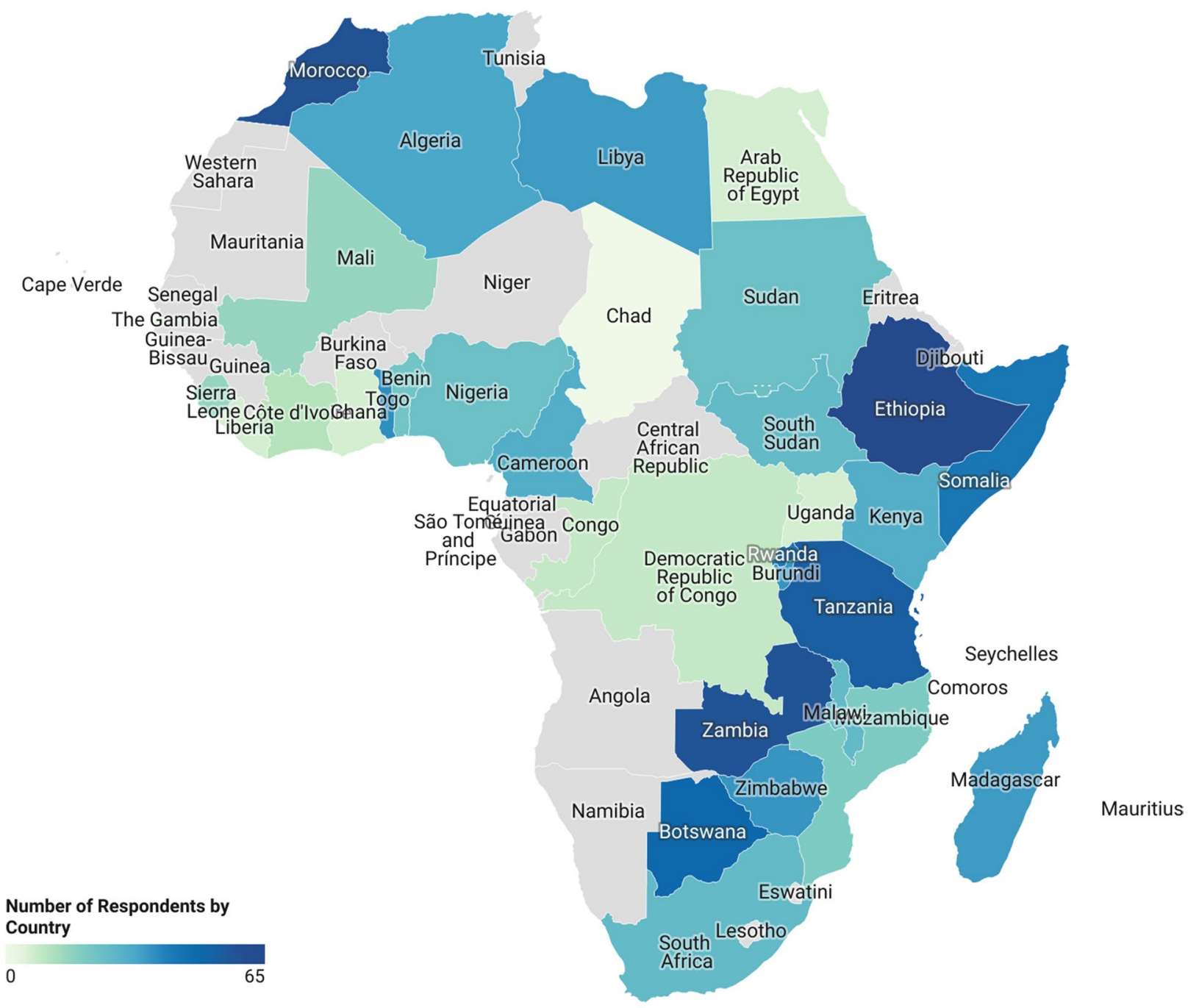

Grey color signifies countries with no respondents. Median number of schools per country $=3$. Interquartile range $=2$

Created with Datawrapper

Fig. 1 Locations of medical students surveyed across the African continent

technological issues (65\%), decreased connection with their classmates $(60 \%)$, and decreased availability of professors (50\%).

When asked about other aspects of the learning envirnoment, $43 \%$ were satisfied with time available for academics, compared with $66 \%$ before the pandemic began $(\mathrm{p}<0.001)$. $37 \%$ of students were satisfied with the volume of material, compared with $79 \%$ before the pandemic $(\mathrm{p}<0.001)$. Students were also less satisfied with peer-to-peer learning opportunities, with $28 \%$ reporting satisfaction compared with $79 \%$ before the pandemic $(\mathrm{p}<0.001)$.

\section{Curricular structure changes related to COVID-19}

\section{Pandemic}

Students reported several changes to the structure of their education. The proportion of students taking exams online increased from 6 to $26 \%$ since the start of the pandemic $(\mathrm{p}<0.001)$. There was additionally a decrease in the proportion of students seeing patients as a part of their education, from 72 to $19 \%(\mathrm{p}<0.001)$. Among students who were seeing patients before the pandemic, $74 \%$ were no longer seeing patients since the start of the pandemic. 


\section{Medical School Suspensions Across Africa}

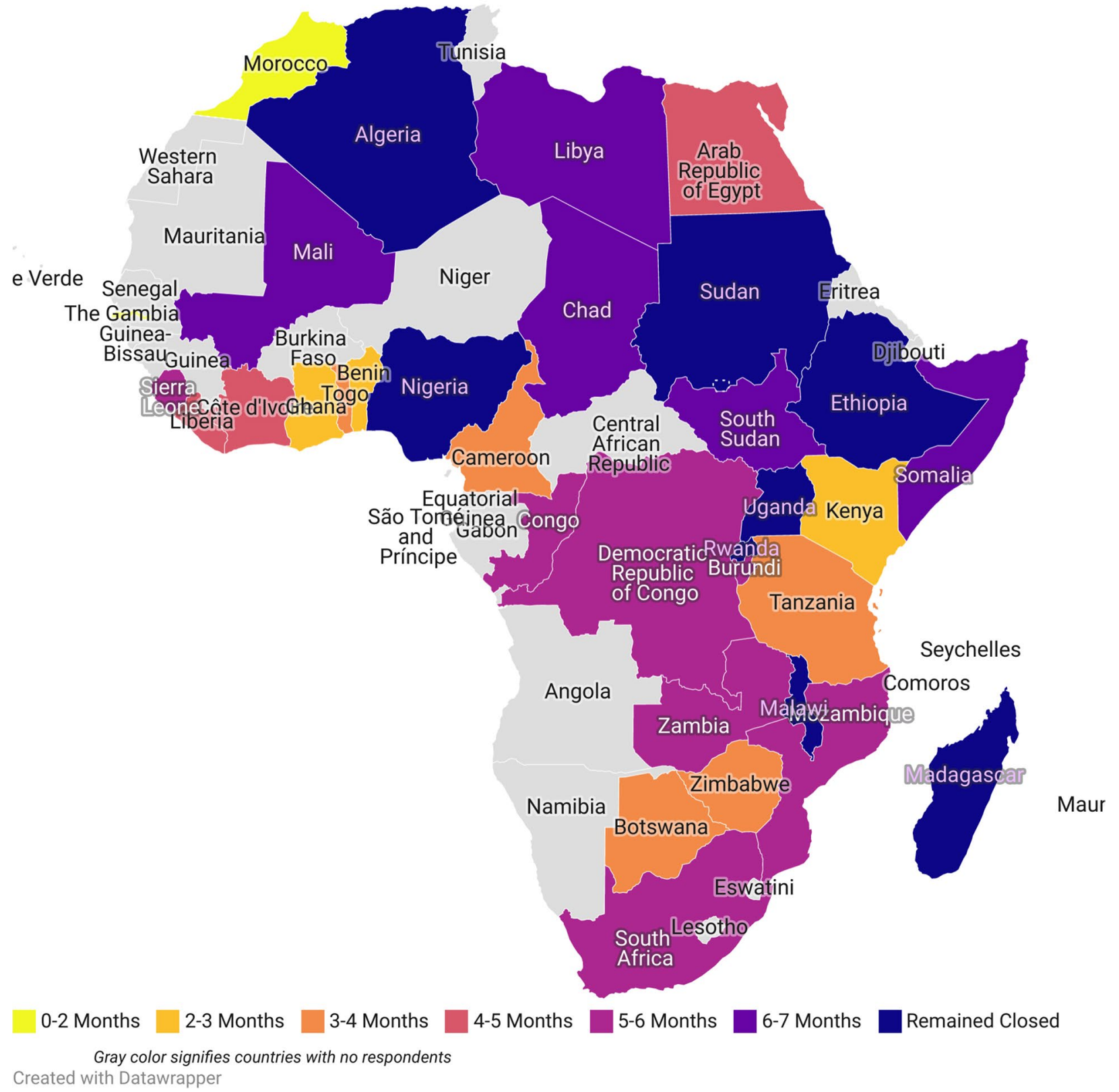

Fig. 2 Average Length of Medical School Closures Across the African Continent

Volunteer activities during the COVID-19 pandemic

Additionally, 29\% of students reported engaging in volunteer activities during the pandemic. These activities included health screening work at hospitals and dormitories, contact tracing, fundraising for charitable causes, educational campains and volunteer tutoring.
Effect of pandemic related changes to mental health

Students reported differering impacts of the pandemic on their mental health, with $44 \%$ reporting a negative change in their mental health, $23 \%$ reporting a positive change, and $34 \%$ reporting no change. Class suspensions were not significantly assoicated with impact on mental health $(\mathrm{p}=0.332)$. There were no significant 


\section{SATISFACTION WITH VARIOUS LEARNING ASPECTS}

(VERY SATISIFIED OR SATISFIED)

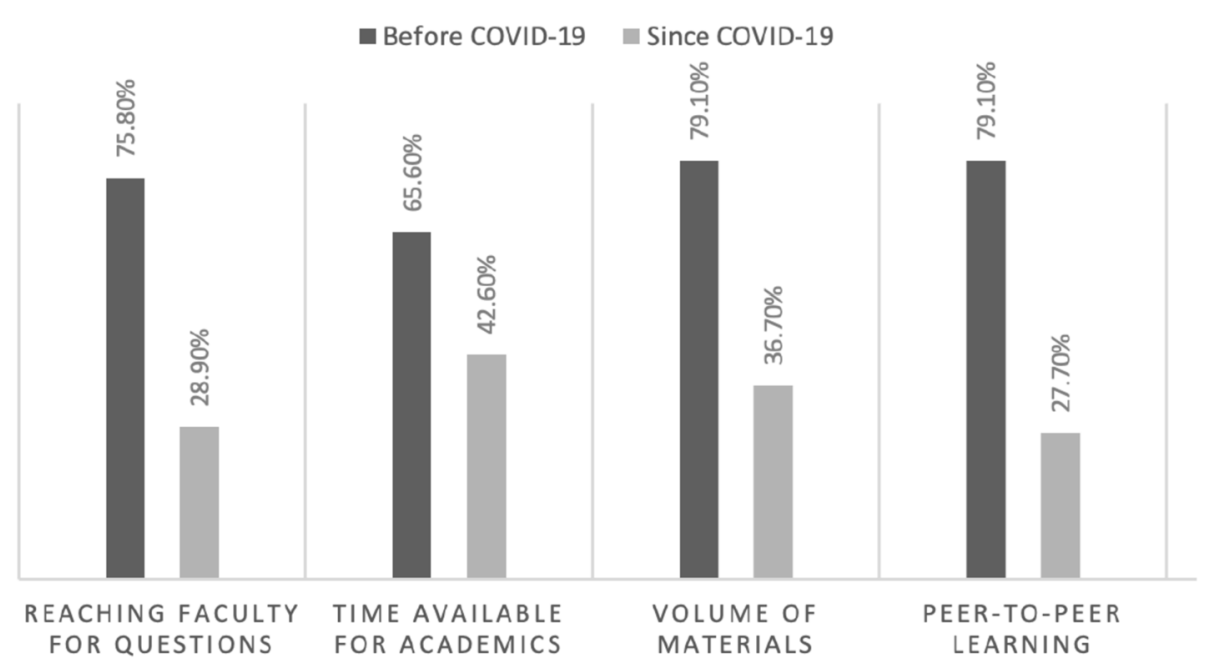

Fig. 3 Proportion of sample reporting high satisfaction with various aspects of the learning environment and proportion of exams administered online before and after the start COVID-19 pandemic

associations between mental health and sex of respondent $(\mathrm{p}=0.519)$.

\section{Discussion}

COVID-19 and associated mitigation measures are harming medical students in Africa, a region already suffering from a severe shortage of trained healthcare workers. The disruption to medical education has similarities and differences from the impact in high-income countries (HIC) countries such as the United States (US). In the US, medical schools are able to follow guidance from the Association of American Medical schools. This guidance included a temporary pause to in-person clinical rotations and shift towards online education [16]. Standards and timelines for testing and graduation requirements were rearranged to meet the demands of the pandemic while ensuring continued focus on learner progress [17]. In Canada, standardized guidance for medical schools resulted in more uniform withdrawals of learners from the clinical space [18]. Across Europe, guidelines directly shifted education online and in central and south America many educational experiences were suspended with a varied level of transition to online learning [19].Medical students in African countries may have suffered from a lack of similar templates to follow as there were few national or continent-wide policies and guidelines in place for reopening and education during shutdowns. Correspondingly, the responses across the African continent were more uneven, with many schools remaining closed for the duration of our survey period and with many schools reopening. This is in contrast to the US, where most medical schools followed guidance on timing from the Association of American Medical Schools [15]. Between March and July 2020, temporary mandates to close all universities (including medical schools) were issued in 44 of 54 countries in Africa [20,21]. Our results add to this context, indicating that majority of medical students had their medical schools closed, with many students not able to resume their medical education even after several months at the end of our study period. Delays and cancellations of medical training have already caused some delay in the entrance of physicians into the workforce and this problem is likely to continue without intervention [21].

The pandemic related changes to medical education have likewise been detrimental to the environment for students. These findings confirm the myriad challenges facing teaching faculty at medical training institutions in Africa from COVID-19 and represent a significant opportunity to improve the learning environment. Most medical schools receive governmental grants to fund research and salary for their medical faculty and the projected economic contraction on the African continent is likely to cause limitations in funding for faculty members, further exacerbating the challenges in the learning environment [21]. Educators across the globe have suffered many new challenges because of the pandemic. In Indonesia, teachers working from home cite new difficulties covering the cost of electricity and internet access and report difficulties maintaining motivation [22]. In the United Kingdom, educators suffered from an increase in 
uncertainty and disruptions to their identity as teachers [23]. A study of educators in India found that in addition to technical support, teachers as well as students benefit from high-quality and timely interactions with each other [24]. Further support for both teachers and students during times of disruption appears to be needed to limit the harm from major societal stressors. For greatest efficacy, interventions should include financial and logistical support for educators as well as clear and collaborative communication and planning with teachers.

Students across Africa endorsed a shift to online learning and exams, although this transition appears to be less drastic than in HIC [25]. The large increase in online testing speaks to the need for robust and reliable internet access and online programming in Africa. Even before COVID-19, there had been a shift towards technology-integrated learning and self-directed work in many medical schools across the world. The pandemic has accelerated these trends, with varying levels of success [26]. However, many countries within Africa lack the reliable broadband access, consistent electricity and advanced smartphones necessary to access online learning content $[27,28]$. A review of the literature suggests that many similar problems have been encountered worldwide. In South Asia, it is estimated that the shift to online learning was accelerated by 5-10 years [29]. There is a need to accommodate this accelerated transition to ensure adequate training of the healthcare workforce, where barriers to online learning have the potential to derail this trend. There are several initiatives currently underway to increase internet access across the continent with recommendations including: Removing roadblocks to infrastructure investment, promoting private sector investment, and involving high levels of political leadership [30, 31]. For the success and stability of future medical education in Africa, this access appears to be critical.

It is important to note that access to the internet is closely connected with many demographic and sociological factors. Notably, persons with disabilities are less likely to have access to computers or to the internet, after controlling for other sociodemographic factors [32]. Personal wealth also plays a large role in access to the internet, although some nations have been more successful at reducing this divide [33]. The digital divide is apparent both on a country level and between induvial within a nation [34-36]. It will be important to both improve country-level infrastructure capabilities and to provide targeted additional support to those sectors of the population who may face increased difficulties with internet connectivity.

The direct impact on student wellbeing in Africa is consistent with a recent global survey of young people that found a majority believe that the pandemic, school closures, and restricted social connections worsened preexisting mental health conditions [37].

Our study had several important limitations. We distributed our survey though student networks, and our response rate varied by country and school, with some medical schools providing few respondents. This may be partially due to the variations in medical school prevalence, with 24 countries in sub-Saharan Africa having only one medical school, and 11 countries having no medical schools [4]. The average number of medical schools per country across Africa is only 1.8 schools [4]. While the use of social media allowed for a greater breadth of country and school respondents, this approach may have created a biased sample as those without access to social media during lockdowns and disruption would have been unable to participate. The prevalence of social media use across medical students in Africa is not known and would benefit from further study. The use of social media also did not allow calculation of the specific population reached by the survey instrument. Our data represent a snapshot of the experience of medical students in Africa to the unprecedented global stressor of COVID-19 and speaks to the need for a deeper assessment of individual-country responses. Additionally, qualitative research was not performed among medical students in Africa in order to inform survey creation and psychometric testing was not done to determine the underlying constructs of the instrument. Nonetheless, we believe these limitations are balanced by the need to rapidly develop and disseminate a highly relevant survey instrument to enable meaningful research that may benefit medical education and, therefore, public health during the COVID-19 pandemic.

Our study findings suggest a brewing problem in medical education across the African continent with an urgent need for solutions. Broadly, the outcomes mentioned here speak to the need for a comprehensive response plan in the event of future disruptions-COVID-19-related or otherwise-that encompasses, at minimum, mental health and logistical support for students and faculty, expanded internet access, and safety planning to minimize disruptions to student education.

\section{Conclusions}

The response of medical schools to the COVID-19 pandemic has the potential to represent a transformational shift in education, a shift toward increased flexibility and adaptability, internet-based learning, and curricular innovation. However, this study highlights the urgent need for flexible and innovative approaches to continuing medical education in Africa. Without an effective mitigation strategy, the current disruption in medical training has the potential to impact medical care and the availability of healthcare workers across the continent in the years to come. 


\section{Supplementary Information}

The online version contains supplementary material available at https://doi. org/10.1186/s12909-021-03038-3.

\section{Additional file 1.}

\section{Acknowledgements}

The authors would also like to acknowledge the following students for their assistance distributing the survey to in-country networks: Khairoon Abdulkadir Mohamed, Kwizera Patrick, Bora Nikuze Lysette, Alameen Hamid Elhaj, Yaaser Hamza, Ngwao Ngwako, Matabof Victor Bitrus, Louisa Munyira, Eric Tetteh Ayertey, Ayebare Trevor Katsirabo, Njofie Clovis, Cheick Oumar Coulibaly, John T Sarboah Jr, Briand Awideya, Habau Atche Yaswa Djanwet, Kholwa Nkambule, Karim Arif Karim, Saad Uakkas, Joëlla Sayubu, Mohamed Moftah Assalhi, Abdiqani Abdilahi, Lawrence Mukeh Babawo, Daoud Hadj Omar, Anita Tsado, Aisha Mohamed Hussein, Owen Chisoti, Clodel Sédric Yamongbè, Annely Henriques Ferrao, Rabearison Andrianavalona Oniarinjava, Matiop Deng Thiong, Panda Auguste Guillaume, Kyrillos Wassim Samir. The authors would like to acknowledge the following group for sharing their survey which was used to create the survey for this study: Dr. Caren Stalburg, Jiwon Park, Andreia Oliveira, and Poorva Patil.

\section{Authors' contributions}

AB contributed to study design, study concept, manuscript review, assisted with data analysis, significant contributed to manuscript preparation and writing, and assisted with statistical analysis of the data. Gl contributed to study design, study concept, manuscript review, data analysis and significantly contributed to manuscript preparation and writing. NB contributed to the study design, study concept, manuscript review, data analysis and significantly contributed to manuscript preparation and writing. AN contributed to survey design and coordinated the distribution among medical students in Africa, and assisted with manuscript review. DT contributed to survey design, coordinated the distribution among medical students in Africa, and assisted with manuscript review. BA contributed to survey design, coordinated the distribution among medical students in Africa, and assisted with manuscript review. EH conducted statistical analysis of the data and assisted with manuscript review. All authors have read and approved the manuscript.

\section{Funding}

Not applicable.

\section{Availability of data and materials}

The datasets used and analysed during the current study are available from the corresponding author on reasonable request.

\section{Declarations}

\section{Ethics approval and consent to participate}

IRB approval was granted via St. Paul's Millennium Medical College Institutional Review Board. All research was performed in accordance with the Declaration of Helsinki and approved by an appropriate ethics committee. Informed consent to participate was elicited prior to survey administration with an option to opt-out prior to survey administration.

\section{Consent for publication}

Not applicable.

\section{Competing interests}

The authors declare that they have no competing interest.

\section{Author details}

${ }^{1}$ University of Michigan Medical School, 48103 Ann Arbor, MI, USA. ${ }^{2}$ St.Paul's Hospital Millennium Medical College, 1271 Swaziland Street, Addis Ababa, Ethiopia.
Received: 29 April 2021 Accepted: 25 November 2021

Published online: 09 December 2021

\section{References}

1. Naicker S, Plange-Rhule J, Tutt RC, Eastwood JB. Shortage of healthcare workers in developing countries - Africa. Ethn Amp Dis. 2009;19(1 Suppl. 1). [cited 2021 Mar 18] Available from: https://www-cabdirect-org.proxy. lib.umich.edu/cabdirect/abstract/20093133945

2. Kinfu Y. The health worker shortage in Africa: are enough physicians and nurses being trained? Bull World Health Organ. 2009;87(3):225-30.

3. WHO Coronavirus Disease (COVID-19) Dashboard. [cited 2021 Feb 7]. Available from: https://covid19.who.int

4. Mullan F, Frehywot S, Omaswa F, Buch E, Chen C, Greysen SR, et al. Medical schools in sub-Saharan Africa. Lancet. 2011;377(9771):1113-21.

5. Chen C, Buch E, Wassermann T, Frehywot S, Mullan F, Omaswa F, et al. A survey of Sub-Saharan African medical schools. Hum Resour Health. 2012;24(1):4.

6. https://plus.google.com/+UNESCO. Education: From disruption to recovery. UNESCO. 2020 [cited 2021 Mar 18]. Available from: https://en.unesco. org/covid19/educationresponse

7. DeWitt DE. Fighting COVID-19: Enabling Graduating Students to Start Internship Early at Their Own Medical School. Ann Intern Med. 2020;21(2):143-4

8. Flotte TR, Larkin AC, Fischer MA, Chimienti SN, DeMarco DM, Fan P-Y, et al. Accelerated Graduation and the Deployment of New Physicians During the COVID-19 Pandemic. Acad Med. 2020;95(10):1492-4.

9. Sandhu P, de Wolf M. The impact of COVID-19 on the undergraduate medical curriculum. Med Educ Online. 2020;25(1):1764740.

10. Barteit S, Jahn A, Banda SS, Bärnighausen T, Bowa A, Chileshe G, et al. E-Learning for Medical Education in Sub-Saharan Africa and LowResource Settings: Viewpoint. J Med Internet Res. 2019;21(1)e12449.

11. Adebisi YA, Agboola P, Okereke M. COVID-19 Pandemic: Medical and Pharmacy Education in Nigeria. Int J Med Stud. 2020;8(2):162-4.

12. Okereke M, Williams AE, Emmanuella NC, Ashinedu NU, Mairaj MW. COVID-19: challenges affecting the uptake of e-learning in pharmacy education in Africa. Pan Afr Med J [Internet]. 2020 Jun 9 [cited 2021 Mar 18];35(Suppl 2). Available from: https://www.ncbi.nlm.nih.gov/pmc/artic les/PMC7875778/

13. Jafari N, Loghmani A, Montazeri A. Mental health of Medical Students in Different Levels of Training. Int J Prev Med. 2012;3(Suppl1):S107-12.

14. Coronavirus disease (COVID-19). [cited 2021 Aug 7]. Available from: https://www-who-int.proxy.lib.umich.edu/emergencies/diseases/novelcoronavirus-2019

15. Hamilton CM, Strader LC, Pratt JG, Maiese D, Hendershot T, Kwok RK, et al. The PhenX Toolkit: Get the Most From Your Measures. Am J Epidemiol. 2011;174(3):253-60.

16. Rose S. Medical Student Education in the Time of COVID-19. JAMA. 2020:2(21):2131.

17. Lucey CR, Johnston SC. The Transformational Effects of COVID-19 on Medical Education. JAMA. 2020;324(11):1033.

18. Johnston A, Barrick K, Jivraj F, Ram R. 'The Virtual Check-In': A tool to facilitate virtual patient interaction for early clinical learners in a longitudinal integrated clerkship. MedEdPublish [Internet]. 2020 [cited 2021 Oct 31];9(1). Available from: https://www.mededpublish.org/manuscripts/3125

19. Gordon M, Patricio M, Horne L, Muston A, Alston SR, Pammi M, et al. Developments in medical education in response to the COVID-19 pandemic: A rapid BEME systematic review: BEME Guide No. 63. Med Teach. 2020:42(1):1202-15

20. Cecilio-Fernandes D, Parisi MCR, Santos TM, Sandars J. The COVID-19 pandemic and the challenge of using technology for medical education in low and middle income countries. MedEdPublish. 2020 [cited 2021 Mar 18];9. Available from: https://www.mededpublish.org/manuscripts/ 3024

21. Ossai EN, Ogbuoji O. Redressing the impact of COVID-19 on medical education in Africa: the need for collective action. BMJ Glob Health. 2021;6(3):e005067.

22. Purwanto A, Asbari M, Fahlevi M, Mufid A, Agistiawati E, Cahyono Y, et al. Impact of Work From Home (WFH) on Indonesian Teachers Performance 
During the Covid-19 Pandemic: An Exploratory Study. Int J Adv Sci Technol. 2020;29(5):11.

23. Kim LE, Asbury K. 'Like a rug had been pulled from under you': The impact of COVID-19 on teachers in England during the first six weeks of the UK lockdown. Br J Educ Psychol. 2020;90(4):1062-83.

24. Nambiar D. The impact of online learning during COVID-19: students' and teachers' perspective. Int J Indian Psychol. 2020;8(2):783-93.

25. Emanuel EJ. The Inevitable Reimagining of Medical Education. JAMA. 2020;24(12):1127.

26. Hilburg R, Patel N, Ambruso S, Biewald MA, Farouk SS. Medical Education During the Coronavirus Disease-2019 Pandemic: Learning From a Distance. Adv Chronic Kidney Dis. 2020;27(5):412-7.

27. Barteit S, Guzek D, Jahn A, Bärnighausen T, Jorge MM, Neuhann F. Evaluation of e-learning for medical education in low- and middle-income countries: A systematic review. Comput Educ. 2020;145:103726.

28. Goh P-S, Sandars J. A vision of the use of technology in medical education after the COVID-19 pandemic. MedEdPublish. 2020;9(1). [cited 2021 Mar 18] Available from: https://www.mededpublish.org/manuscripts/ 2943

29. Piryani RM, Piryani S, Piryani S, Shankar PR, Shakya DR. Impact of COVID-19 Pandemic on Medical Education: Challenges and Opportunities for Medical educators in South Asia. J BP Koirala Inst Health Sci. 2020;3(1):28-38

30. Schumann R, Kende M. Lifting barriers to Internet development in Africa: suggestions for improving connectivity. Analysys Mason Limited, London. 2013;9:30-5.

31. Kyem PA. Mobile phone Expansion and Opportunities for E-Governance in Sub-Saharan Africa. The Electron J Inf Syst Developing Ctries. 2016;75(1):1-5.

32. Dobransky K, Hargittai E. The disability divide in internet access and use. Inf Commun Soc. 2006;9(3):313-34.

33. Howard PN, Busch L, Sheets P. Comparing digital divides: Internet access and social inequality in Canada and the United States. Can J Commun. 2010;35(1).

34. Ngini CU, Furnell SM, Ghita BV. Assessing the Global Accessibility of the Internet. Internet Res. 2002;12(4):329-8.

35. West DM. Digital divide: Improving Internet access in the developing world through affordable services and diverse content. Center for Technology Innovation at Brookings. 2015. p. 1-30.

36. Jackson LA, Barbatsis G, Eye AV, Biocca F, Zhao Y, Fitzgerald H. Internet use in low-income families: Implications for the digital divide. IT Soc. 2003;1(5)141-65.

37. Coronavirus Report: Impact on Young People with Mental Health Needs. YoungMinds. [cited 2021 Mar 18]. Available from: https://youngminds. org.uk/resources/reports/our-impact-reports/

\section{Publisher's Note}

Springer Nature remains neutral with regard to jurisdictional claims in published maps and institutional affiliations.

Ready to submit your research? Choose BMC and benefit from:

- fast, convenient online submission

- thorough peer review by experienced researchers in your field

- rapid publication on acceptance

- support for research data, including large and complex data types

- gold Open Access which fosters wider collaboration and increased citations

- maximum visibility for your research: over 100M website views per year

At BMC, research is always in progress.

Learn more biomedcentral.com/submissions 